\title{
A COMPARATIVE STUDY ON THE PERCEPTION OF DENTAL ESTHETICS OF LAYPERSONS AND DENTAL STUDENTS
}

\author{
IULIANA BABIUC ${ }^{1}$, IOANA-IOESEFINA OPINCARU ${ }^{2}$, MIHAELA PĂUNA ${ }^{3}$, \\ MIHAI BURLIBAȘA ${ }^{4}$, GABRIELA TĂNASE ${ }^{5}$, LILIANA BURLIBAȘA ${ }^{6}$, IRINA DONCIU ${ }^{7}$, \\ IRINA ADRIANA BEURAN ${ }^{8}$, ILEANA IONESCU ${ }^{9}$, CAMELIA IONESCU ${ }^{10}$ \\ 1,2,3,4,5,7,8,9,10 “Carol Davila” University of Medicine of Pharmacy Bucharest, ${ }^{6}$ University of Bucharest
}

\begin{abstract}
Keywords: $\quad$ esthetic Abstract: Introduction: Esthetic dentistry aims to create a harmonious smile that is well integrated with perception, smile design, the facial architecture of the patient. A good understanding of the patient's esthetic perception is dental esthetics, gingival important when designing a smile. Materials and methods: 106 subjects, 51 patients 54 dental students harmony took part in the study. Each subject was asked to evaluate 10 pictures showing frontal aspect of real cases. They were asked to rate the aesthetics of the clinical cases on a scale from 1 to 5 . An open question was associated with each picture, where the subjects were asked to describe what they like and what they do not like about the picture. Results and discussions: The overall mean esthetic rating of dental students was 2,68, while the laypersons' rating was 2,98. Crowded teeth are more often criticized by patients, while dental students consider that slight crowding give a more natural appearance and individualize the teeth. The presence of diastema is observed by dental students even when it is discrete. The discrepancy between maxillary and mandibular dental midline is more easily observed by dental students. Discolored teeth lead to low aesthetic scores for both groups of subjects. Dental students gave lower esthetic scores to restorations with uniform colour, while laypersons appreciate white restorations. The limited height of papillae is considered unattractive by dental students, while laypersons hardly notice this aspect. Conclusions: This study showed several differences in the aesthetic perception of dental students and laypersons. Students were generally more critical and gave lower scores than laypersons. They also observed and criticized more aspects regarding the smile.
\end{abstract}

\section{INTRODUCTION}

Esthetic dentistry aims to create a harmonious smile that is well integrated with the facial architecture of the patient. Smile design relies on several facial and dental parameters that need to be accounted for in order to obtain consistent esthetic outcomes.(1) The difference in aesthetic perception of dental professionals as compared to laypersons has been observed throughout several studies. Most of them involve digitally modified images that change several parameters of the smile aesthetics.(2-4)

In a study where 96 subjects (dentists, dental technicians and laypersons) analyzed the ideal proportion of the maxillary central incisor, a preference for $82 \%$ ratio has been reported. Extreme values have been unanimously been considered non-aesthetic. Differences have been noticed between laypersons' perception of tooth wear and late eruption, which was overlooked, while dental professionals gave a lower score.(5) The wear of the canine cuspid did not influence the aesthetic perception. The deviation of the midline was noticeable to the groups of subjects in a different degree: orthodotists noticed a $1 \mathrm{~mm}$ shift of the midline, prosthodontists observed a $2 \mathrm{~mm}$ shift, while the patients did not notice the shift at all.(6) A vertical axial midline angulation of $3,5^{\circ}$ can be perceived by laypersons. If the canting was in the same direction as the asymmetry of the face, it was rated more attractive than the instance where the canting was in the opposite direction.(2) Another study found that a tilt of $2 \mathrm{~mm}$ of the vertical axis of the maxillary central incisor is visible for all groups of subjects.(7)
A $2^{\circ}$ deviation of the occlusal plane from a transversal perspective is noticeable for laypersons, when the vertical landmarks of the face present a deviation up to $3 \mathrm{~mm}$. The transversal occlusal plane should be parallel to the interpupillary line, or an angulation of less than $2^{\circ}$ is preferable.(3) A step of $1 \mathrm{~mm}$ between the incisal margin is considered by dentists as non-aesthetic, while patients considered a step of at least $3 \mathrm{~mm}$ unacceptable. When the maxillary central incisor's gingival margin symmetry was observed, dentists noticed a $0,5 \mathrm{~mm}$ discrepancy, while patients only noticed a $2 \mathrm{~mm}$ difference.(6)

The gingival exposure of $2 \mathrm{~mm}$ was considered nonaesthetic from the orthodontists' perspective, while the rest of the dentists and the patients found it unpleasant when a $4 \mathrm{~mm}$ exposure was present.(7) Dentists consider the shortening of the height of the papillae as unattractive, even for small discrepancies. $(8,9)$

\section{AIM}

This study aims at comparing the personal aesthetic perception of dental students with that of laypersons' using images of real cases.

\section{MATERIALS AND METHODS}

106 subjects took part in the study. 51 were randomly selected patients from a private practice in Bucharest, Romania. 54 subjects were dental students in the $6^{\text {th }}$ year at the Faculty of Dentistry, "Carol Davila" University of Medicine and Pharmacy Bucharest, Romania.

\footnotetext{
${ }^{4}$ Corresponding author: Mihai Burlibașa, Str. Plevnei, Nr. 19 Sector 1, București, România, E-mail: mburlibasa@gmail.com, Phone: +40723 472632
} Article received on 02.05.2020 and accepted for publication on 02.06.2020 


\section{CLINICAL ASPECTS}

Each subject was asked to evaluate 10 pictures showing frontal aspect of real cases, with different tooth and gingival configurations, according to their own notions of beauty. They were asked to rate the aesthetics of the clinical cases on a scale from 1 to 5 , with 1 representing the least attractive and 5 the most attractive. An open question was associated with each picture, where the subjects were asked to describe what they like and what they do not like about the picture.

\section{RESULTS AND DISCUSSIONS}

The results of the study are included in table no 1 .

Table no 1. Mean esthetic score of dental students and laypersons and the corresponding images selected for evaluation

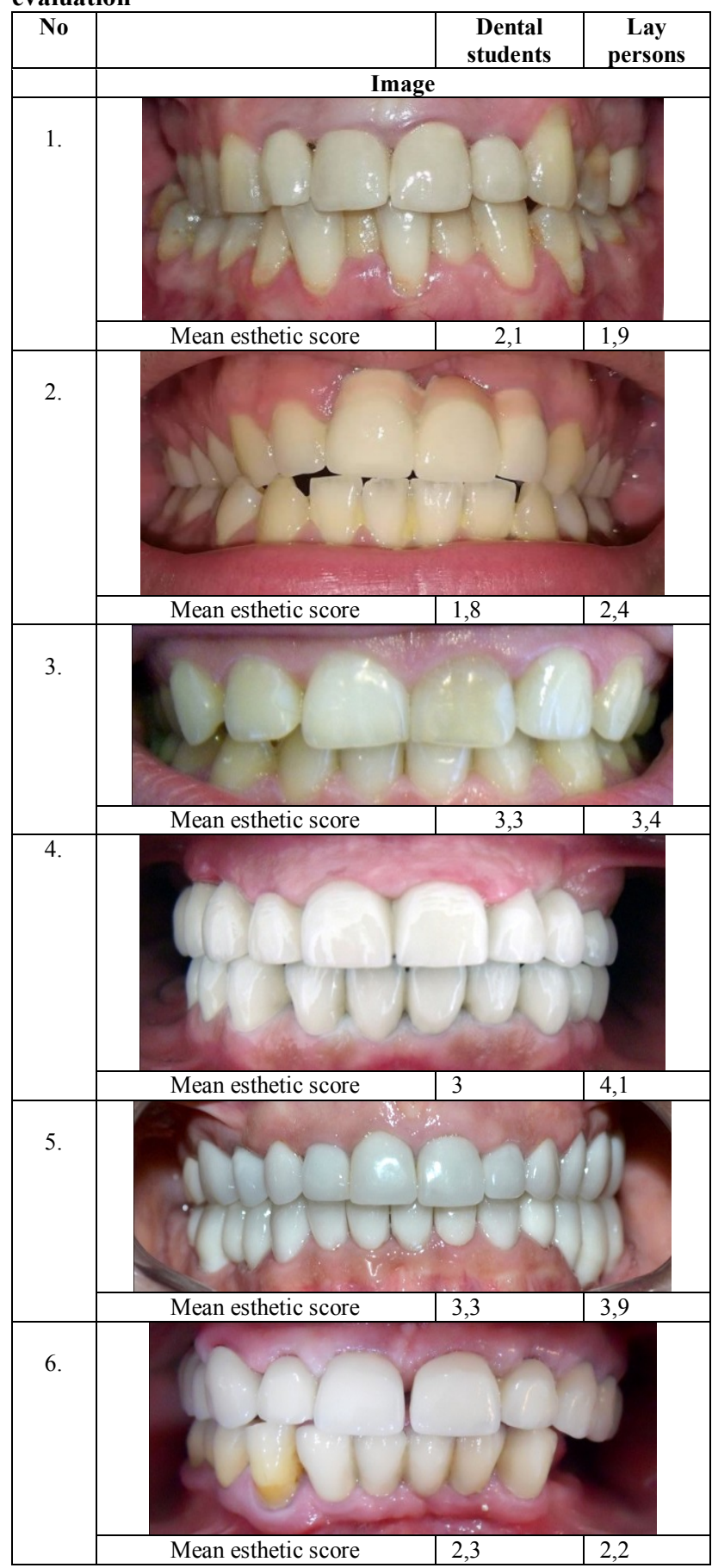

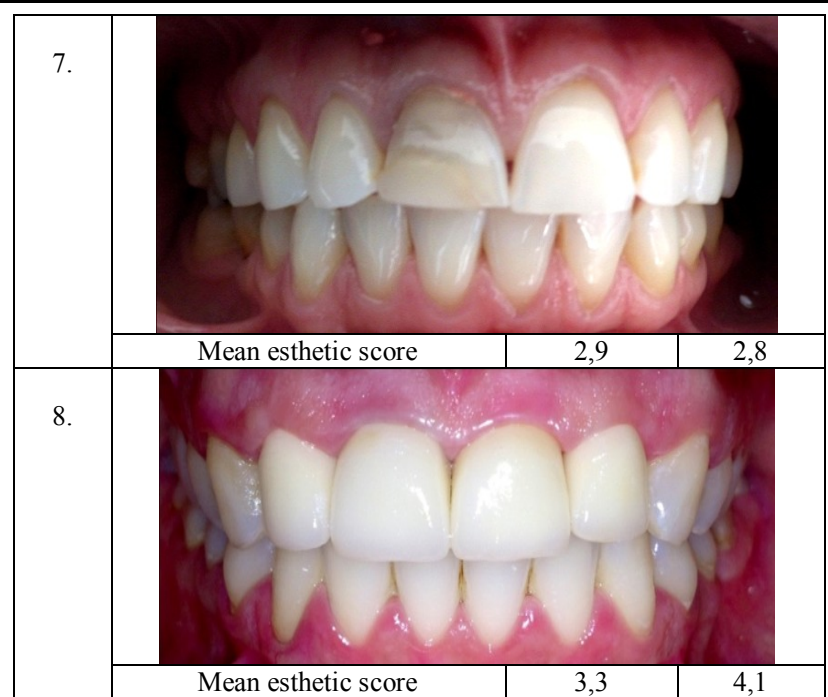
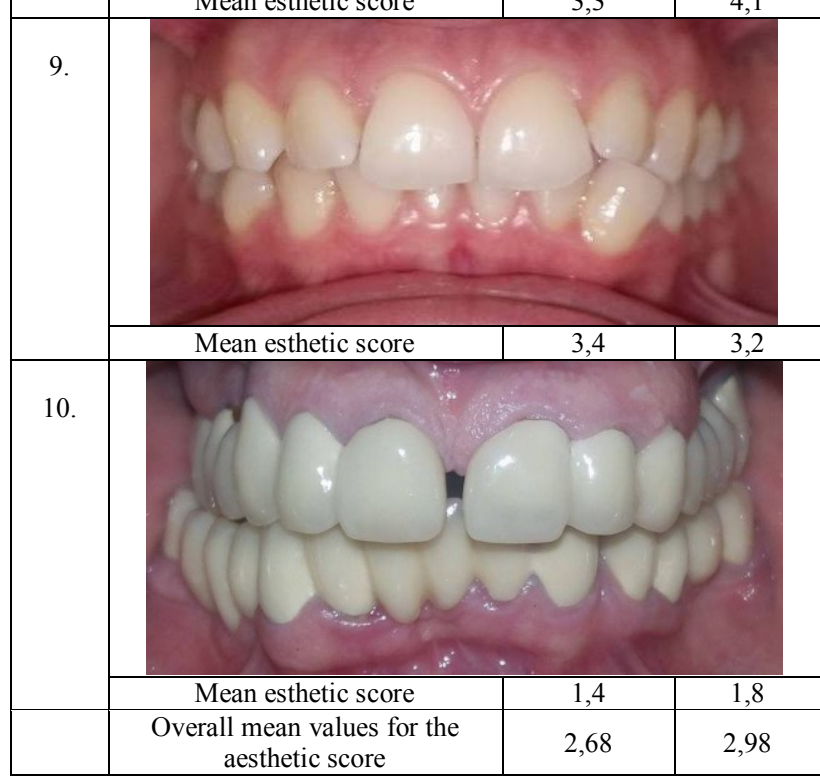

Our findings showed that dental students were generally more critical and gave lower scores than laypersons. Students generally offered more information about the case than laypersons, which suggests dental education provides more aspects to take into consideration when assessing a smile.

Some of the images received comparable scores from both groups of subjects, such as image no 6. Dental students criticized the canted occlusal plane, the presence of diastema and the bulky appearance of the restorations. Both groups of subjects noticed the inflammatory aspect of the papillae, the gingival retraction of the right mandibular canine and the edentulous space left unrestored in the $3^{\text {rd }}$ quadrant.

Other images were rated differently by laypersons and students, suggesting that dental education can alter the perception about dental esthetics, gingival appearance and harmonious smile.

An example is the image no 4, where dental students rated significantly less the aesthetic characteristics of this case as compared to laypersons.

Dental students considered the colour of the restorations unnatural. The students also criticized the canting of the axial midline and a discrepancy between the maxillary and mandibular dental midline. The asymmetry of the centrals, both in form and in proportions was observed. The visible soldering of the teeth also caused lower rating scores. Gingival inflammation and the colour and volume change were noticed. 


\section{CLINICAL ASPECTS}

For the lower restorations, the greyish tint of the soft tissue compromised the aesthetic result.

Figure no. 1. The distribution of the esthetic scores for Image no 6 given by dental students and laypersons

\section{Esthetic scores for Image no 6}

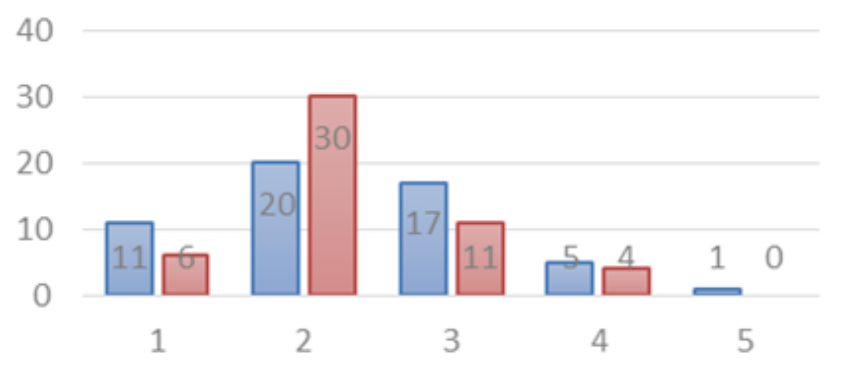

$\square$ Dental students $\square$ Laypersons

Laypersons, on the other hand, appreciated the colour of the restorations. Both groups criticized the bulking of the maxillary teeth and the uneven position of the gingival margin.

This image received a mean score of 3 out of 5 from dental students and 4,1 out of 5 from laypersons' perspective.

Figure no. 2. The distribution of the esthetic scores for Image no 4 given by dental students and laypersons

Esthetic scores for Image no 4

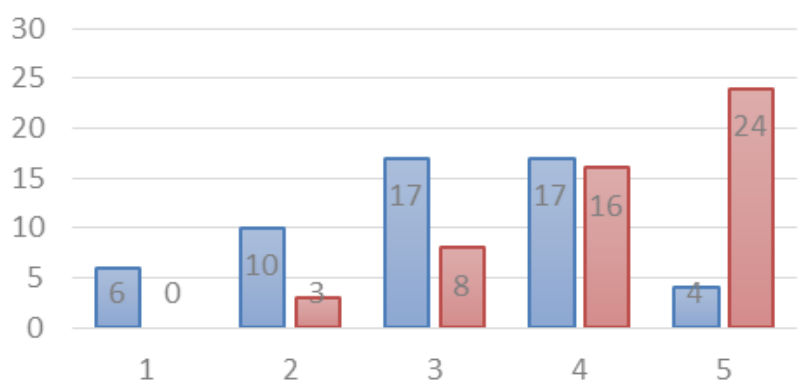

$\square$ Dental students $\square$ Laypersons

Our results confirmed that tilting of the axial midline is visible to all groups of subjects, just as stated in previous studies.(2,7) Laypersons were less receptive about the discrepancy in position of the incisal edge of maxillary central incisors than dental students. Small deviation of the axial dental midline goes frequently unnoticed by laypersons, a result that is in accordance with other studies. $(6,7)$

Crowded teeth are more often criticized by patients, while dental students consider that slight crowding give a more natural appearance and individualize the teeth. The presence of diastema is observed by dental students even when it is discrete.

Visible discoloured teeth lead to low aesthetic scores for both groups of subjects. Dental students gave lower esthetic scores to restorations with uniform colour, while laypersons appreciate white restorations. Laypersons are more focused on dental parameters like colour and shape and generally oversee the gingival appearance. They pay less attention on the amount of gingival display or the height of papillae, just as described in previous studies. $(8,9)$ The limited height of papillae is considered unattractive by dental students, while laypersons hardly notice this aspect. A small discrepancy of the position of the gingival margin was also overlooked by patients. However, a change in colour caused by inflammation can be visible to laypersons.(10-14)
CONCLUSIONS

This study showed several differences in the aesthetic perception of dental students and laypersons.

Students were generally more critical and gave lower scores than laypersons. They also observed and criticized more aspects regarding the smile.

Acknowledgement: In this article, all the authors have equal contribution with the first author.

\section{REFERENCES}

1. Coachman C, Calamita M. Digital smile design: a tool for treatment planning and communication in esthetic dentistry. Quintessence Dental Technology; 2012:1-9.

2. Silva BP, Jimenez-Castellanos E, Stanley K, Mahn E, Coachman C, Finkel S. Layperson's perception of axial midline angulation in asymmetric faces. $\mathrm{J}$ Esthet Restor Dent. 2018;30(2):119-125.

3. Silva BP, Tortora SC, Stanley K, Mahn G, Coachman C, Mahn E. Layperson's preference of the transverse occlusal plane in asymmetric facial model. J Esthet Restor Dent. 2019;31(6):620-626

4. Silva BP, Mahn E, Stanley K, Coachman C. The facial flow concept: An organic orofacial analysis - the vertical component. J Prosthet Dent. 2019;121(2):189-194.

5. Cooper G, Tredwin C, Cooper N, Petrie A, Gill D. The influence of maxillary central incisor height-to-width ratio on perceived smile aesthetics. BDJ. 2012;212(12):589-599.

6. Pinho S, Ciriaco C, Faber J, Lenza M. Impact of dental asymmetries on the perception of smile esthetics. American Journal of Orthodontics and Dentofacial Orthopedics. 2007;132(6):748-753.

7. Kokich V, Asuman Kiyak H, Shapiro P. Comparing the perception of dentists and lay people to altered dental esthetics. Journal of Esthetic and Restorative Dentistry. 1999;11(6):311-324

8. Yu Y, Alamri A, Francisco H, Cho S, Hirsch S. Interdental papilla length and the perception of aesthetics in asymmetric situations. International Journal of Dentistry. 2015;2015:1-5.

9. Thomas M, Reddy R, Reddy BJ. Perception differences of altered dental esthetics by dental professionals and laypersons. Indian J Dent Res. 2011;22:242-247.

10. Eftimie-Totu E, Cristache $\mathrm{CM}$, Isildak $\mathrm{S}$, Yildirim $\mathrm{R}$, Burlibașa M, Nigde M, Burlibașa L. Preliminary studies on citotoxicity and genotoxicity assesment of the PMMA $\mathrm{TiO}_{2}$ nanocompozites for stereolithographic complete dentures manufacturing. Revista de Chimie. 2018;65:11601165 .

11. Bodnar DC, Burlibașa L, Vârlan C, Marcov N, Georgescu SR, Marcov CE. Mercury, biocompatibility and its impact on environment. Metalurgia International. 2009;14:95-100.

12. Burlibașa M, Tănase $G$, Muntianu L, Murgu AI, Teodorescu E, Malița C. Quality of life, a multidisciplinary concept with economic and social impacts in medical practice. Metalurgia International. 2010; Vol. XV, Spec. Issue No. 4, p. 88-90.

13. Mocuța D, Popovici IA, Burlibașa L, Cristache G, Sfeatcu $\mathrm{R}$, Bodnar T. Impact of the living conditions on population health. Metalurgia International. 2009;14:17-19.

14. Ionescu CA, Popovici LR, Mocuța D, Malița C, Burlibașa M. The quality of human life from the perspective of sustainable development. Metalurgia International. 2009;14:41-43. 